\title{
Novel bifunctional chiral squaramide-amine catalysts for highly enantioselective addition of mono- and diketones to nitroalkenes
}

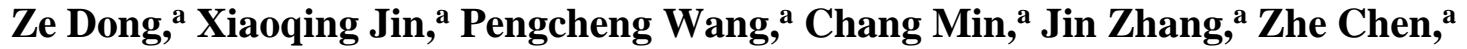 \\ Hai-Bing Zhou, a,b and Chune Donga,b* \\ ${ }^{a}$ State Key Laboratory of Virology, College of Pharmacy, Wuhan University, \\ Wuhan 430071, China \\ ${ }^{b}$ Key Laboratory of Organofluorine Chemistry, Shanghai Institute of Organic Chemistry, \\ Chinese Academy of Sciences, Shanghai 200032, China \\ E-mail: cdong@whu.edu.cn
}

\begin{abstract}
Novel bifunctional chiral squaramide-amine organocatalysts have been developed by rational combination of pyrrolidine and a cinchona alkaloid. The catalysts promoted the enantioselective Michael addition of both mono- and diketones to a broad range of nitroalkenes providing the corresponding products in moderate to high yields with excellent enantioselectivities and diastereoselectivities (up to $96 \%$ yield, $96 \%$ ee, 98:2 $d r$ ) under mild conditions. These results demonstrate that the assembly of two chiral privileged skeletons, pyrrolidine and cinchonine with a squaramide linker is a useful strategy to reach a wider substrate scope, high reaction efficiency and enantioselectivity. The match of the chiralities between two backbones embedded in the catalysts is also critical for improving enantioselectivity.
\end{abstract}

Keywords: Chiral squaramide-amine, organocatalyst, asymmetric Michael addition, pyrrolidine, cinchonine

\section{Introduction}

In the past decade, the organocatalytic asymmetric Michael reaction has emerged as one of the most important carbon-carbon bond forming reactions in organic chemistry. ${ }^{1}$ In particular, the conjugate addition of ketones to nitroolefins has received extensive attention since the resulting nitroalkanes are versatile intermediates, in which the nitro group can be transformed into various useful functional groups. ${ }^{2}$ Stimulated by the seminal works of List, Barbas and co-workers, ${ }^{3}$ several research groups focused on the development of more efficient primary, ${ }^{4}$ secondary, ${ }^{5}$ amine-based catalysts and also thioureas, in order to both improve the selectivity and substrate scope. ${ }^{6}$ The development of multifunctional chiral organocatalysts is of great importance. ${ }^{7}$ In 
2006, the Jacobsen group successfully applied bifunctional thiourea catalysts to Michael addition and achieved good results. ${ }^{8}$ Recently, the Xiao group developed new thiourea-amine organocatalysts by combining two privileged backbones into one, in the generation of highly efficient catalysts for Michael reaction. ${ }^{9}$ Despite the progress in this area, the existing catalytic systems are still limited. Therefore, new strategies to design more efficient chiral catalysts for this type of reaction are highly desirable.

In addition, squaramides have been studied in molecular recognition, ${ }^{10}$ supramolecular assemblies, ${ }^{11}$ and chiral organocatalysts for asymmetric transformations. ${ }^{12}$ It is known that these molecules also exhibit a dual donor-acceptor hydrogen bonding ability. Due to its unique structure feature and wide application, squaramide still has great potential to explore in asymmetric catalysis. To the best of our knowledge, there is no report on the development of new squaramide-amine bifunctional catalysts by combination of two backbones, which are connected by a squaramide motif. In continuation of our interest in developing new squaramides that are of potential in asymmetric catalysis ${ }^{13}$ we envisioned that the assembly of two privileged frameworks with a squaramide linker would constitute a new class of bifunctional organocatalysts, and the well-defined, rigid, bifunctional squaramide would serve as an efficient stereocontrol element for asymmetric Michael reaction. Herein, we describe the synthesis of unprecedented squaramide-amine bifunctional catalysts by rational incorporation of structurally privileged pyrrolidine, ${ }^{14}$ and cinchona alkaloids, ${ }^{15}$ into one molecule.

The pyrrolidine structural unit can also be replaced with appropriate functionalities, such as 3,5-bis(trifluoromethyl)benzylamine, ${ }^{12}$ 2-amino-1,2-diphenyl-ethanol and prolinol, ${ }^{16}$ as illustrated in Scheme 1. These squaramide bifunctional catalysts proved to be highly efficient for Michael addition of both mono- and diketones to a broad range of nitroalkenes, affording the products in high yields with excellent enatioselectivities and diastereoselectivities.

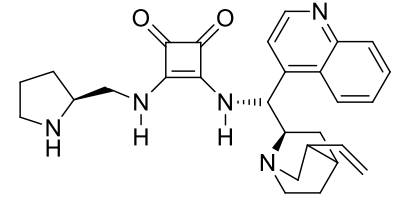

1 a

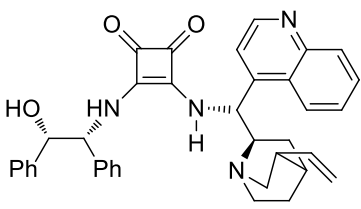

$2 a$

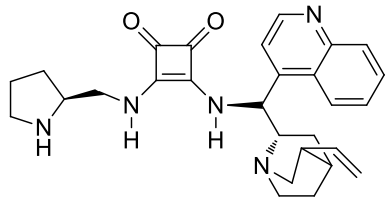

$1 b$

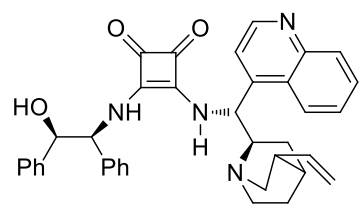

$2 b$

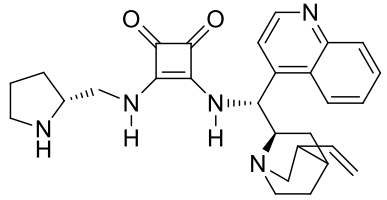

$1 \mathrm{c}$

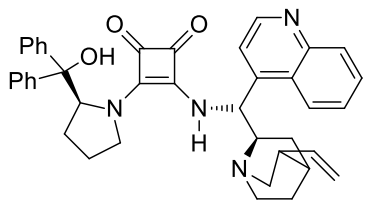

3

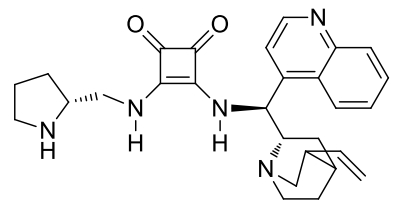

1d

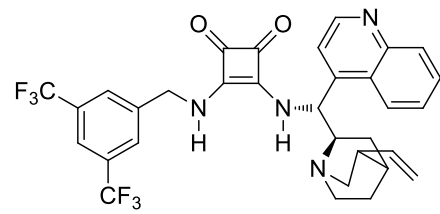

4

Scheme 1. New class of bifunctional chiral squaramide-amine catalysts $\mathbf{1 - 3}$ and previously reported catalyst 4 . 


\section{Results and Discussion}

A series of squaramide-based catalysts (Scheme 1) were prepared and applied to enantioselective Michael addition reactions. The catalysts were easily synthesized by sequential additionelimination reactions of two amines with diethyl squarate 5 (3,4-diethoxy-3-cyclobutene-1,2dione). The synthetic procedure is illustrated in Scheme 2. Treatment of (S)-2-aminomethyl-1- $N$ Boc-pyrrolidine $\mathbf{6}$ with one equivalent of diethyl squarate 5 in the presence of triethylamine in ethanol at room temperature gave the corresponding squaric monoamide monoester $\mathbf{7}$ in $87 \%$ yield. Subsequently, the reaction of $\mathbf{7}$ with the cinchonine-derived amine $\mathbf{8}$ under the same reaction conditions afforded the Boc-protected squaramide-amine 9 (73\%), which was then deprotected directly with $\mathrm{HCl}$ to give the desired organocatalyst 1a in $88 \%$ yield. Other squaramide-amine catalysts $\mathbf{1 b}-\mathbf{d}, \mathbf{2}$ and $\mathbf{3}$ were synthesized by a similar procedure. The structures of the catalysts 1-3 were fully characterized (see the Supporting Information).

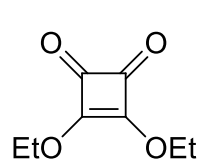

5

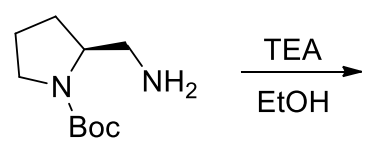

6

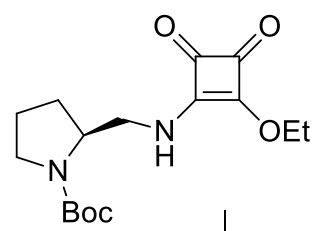

Boc

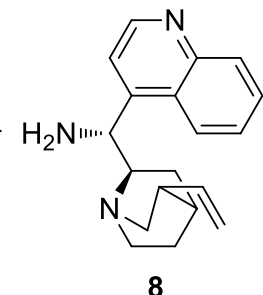

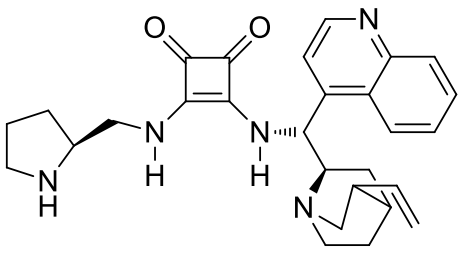

$1 \mathrm{a}$

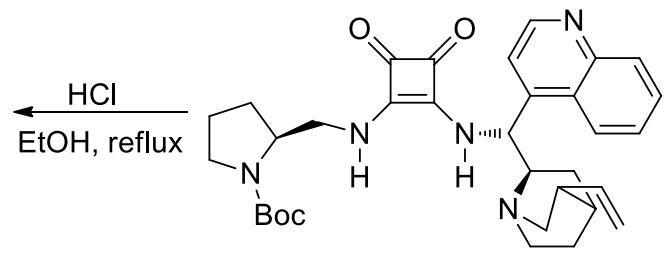

9

Scheme 2. Synthetic route for catalyst 1a.

Initially, the Michael addition of a monoketone was investigated. A brief survey of reaction conditions was carried out for the reaction of cyclohexanone 10 with trans-nitrostyrene 11a using 1a as catalyst (Table 1). We found that the solvent, catalyst loading, and acid additive are critical determinants of the reaction efficiency. Ultimately, we found that the use of $10 \mathrm{~mol} \% \mathbf{1 a}$ and $10 \mathrm{~mol} \%$ of $\mathrm{PhCO}_{2} \mathrm{H}$ in THF is the preferred catalyst system for achieving good yield and high enantioselectivity (Table 1, entry 4). Reducing or enhancing the catalyst loading did not benefit the enantioselectivity at all. It is noteworthy that the reaction proceeded much more slowly and only trace amount of the product was observed in the absence of $\mathrm{PhCO}_{2} \mathrm{H}$ (Table 1, entry 11). Other substituted benzoic acids such as $o$-nitrobenzoic acid, $p$-bromobenzoic acid, $p$ - 
methylbenzoic acid, and TFA gave the product in lower diastereoselectivity or enantioselectivity. The result indicated that the nitrogen atom of the cinchonine as well as the benzoic acid may orientate the nitro group through a hydrogen bonding interaction, so that the cyclohexanone pyrrolidine enamine attacks the nitrooalkene as a nucleophile from a specific face to give the high enantio- and diastereoselectivity. So in all the reactions investigated, $10 \mathrm{~mol} \%$ of $\mathrm{PhCO}_{2} \mathrm{H}$ was used as additive.

The effectiveness of several related chiral squaramides was also evaluated. As shown in Table 1, the combinations of the pyrrolidine with a cinchona alkaloid do indeed play an important role in the stereocontrol in this Michael addition. For chiral squaramide-amine 1a, derived from L-proline and cinchonine, in the addition of cyclohexanone $\mathbf{1 0}$ to nitrostyrene 11a, always displayed higher selectivity. However, when cinchonidine was incorporated into the catalyst backbone (catalyst 1b), both the yield and enantioselectivity of Michael adduct decreased (Table 1, entries 1 vs 12). For catalyst 1c, which was prepared from D-proline and cinchonine, inferior results were observed (entry 13). The catalyst 1d, derived from the D-proline and cinchonidine, induced higher enantioselectivity than those of $\mathbf{1 b}-\mathbf{c}$, the opposite enantiomeric product was generated in 52\% yield and 68\% ee, respectively (entry 14). In contrast, catalysts 2 and $\mathbf{3}$, which possess 2-amino-1,2-diphenylethanol and prolinol moieties, gave no product in this reaction. Surprisingly, the known catalyst $4,{ }^{12 a}$ which exhibits excellent enantioselectivity in catalyzing Michael reaction of diketones and nitroalkenes, showed no activity in conjugate addition of cyclohexanone $\mathbf{1 0}$ to nitrostyrene 11a (Table 1, entry 18). These results demonstrated that the presence of two chiral privileged skeletons, pyrrolidine and cinchonine, with a squaramide linker improve the performance of the catalyst, which is a useful strategy to reach a wider substrate scope, high reaction efficiency and enantioselectivity, justifying the design concept.

Table 1. Optimization and catalyst screening for Michael addition of cyclohexanone $\mathbf{1 0}$ with nitrostyrene 11a ${ }^{\mathrm{a}}$

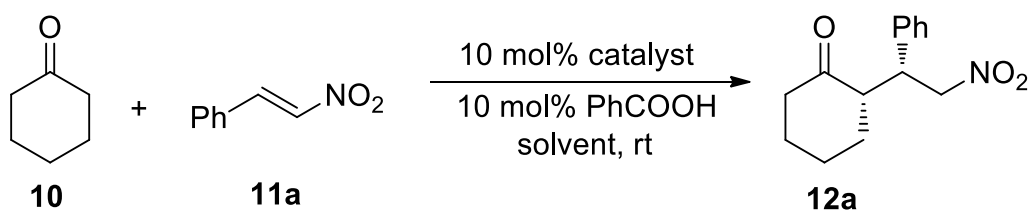

\begin{tabular}{ccccc}
\hline Entry & Cat. & Solvent & Yield $(\%)^{\text {b,c }}$ & ee (\%) \\
\hline 1 & $\mathbf{1 a}$ & toluene & $56(96: 4)$ & 74 \\
2 & $\mathbf{1 a}$ & $\mathrm{CH}_{2} \mathrm{Cl}_{2}$ & $30(96: 4)$ & 93 \\
3 & $\mathbf{1 a}$ & $\mathrm{MeOH}$ & $\mathrm{NR}$ & \\
4 & $\mathbf{1 a}$ & $\mathrm{THF}$ & $60(88: 12)$ & 93 \\
$5^{\mathrm{e}}$ & $\mathbf{1 a}$ & $\mathrm{THF}$ & Traces & $\mathrm{ND}$ \\
6 & $\mathbf{1 a}$ & $\mathrm{CH}_{3} \mathrm{CN}$ & $28(88: 12)$ & 85 \\
\hline
\end{tabular}


Table 1. Continued

\begin{tabular}{ccccc}
\hline Entry & Cat. & Solvent & Yield $(\%)$ b,c & ee $(\%)$ d \\
\hline 7 & $\mathbf{1 a}$ & 1,4-dioxane & $31(93: 7)$ & 9 \\
8 & $\mathbf{1 a}$ & $n$-hexane & $42(97: 3)$ & 74 \\
9 & $\mathbf{1 a}$ & DMF & $\mathrm{NR}$ & \\
10 & $\mathbf{1 a}$ & neat & $68(90: 10)$ & 66 \\
$11^{\mathrm{f}}$ & $\mathbf{1 a}$ & toluene & traces & \\
12 & $\mathbf{1 b}$ & toluene & $44(92: 8)$ & 59 \\
13 & $\mathbf{1 c}$ & toluene & $50(90: 10)$ & $58^{\mathrm{g}}$ \\
14 & $\mathbf{1 d}$ & toluene & $52(90: 10)$ & $68^{\mathrm{g}}$ \\
15 & $\mathbf{2 a}$ & toluene & $\mathrm{NR}$ & \\
16 & $\mathbf{2 b}$ & toluene & $\mathrm{NR}$ & \\
17 & $\mathbf{3}$ & toluene & $\mathrm{NR}$ & \\
18 & $\mathbf{4}$ & toluene & $\mathrm{NR}$ & \\
\hline
\end{tabular}

${ }^{\mathrm{a}}$ Unless otherwise noted, the reactions were carried out with $0.2 \mathrm{mmol}$ of $11 \mathrm{a}, 2.0 \mathrm{mmol}$ of cyclohexanone 10 in the presence of $10 \mathrm{~mol} \%$ of catalyst $1 \mathrm{a}$ and $10 \mathrm{~mol} \%$ of $\mathrm{PhCO}_{2} \mathrm{H}$, in $1.0 \mathrm{~mL}$ of solvent indicated, for $48 \mathrm{~h}$, 'bsolated yield for both diastereomers, ${ }^{\mathrm{c}}$ Numbers in parenthesis correspond to the syn/anti ratio determined by ${ }^{1} \mathrm{H}$ NMR spectroscopy, ${ }^{\mathrm{d}}$ Enantiomeric excess of major diasteroisomer, determined by HPLC on AD-H chiral column, ${ }^{e}$ Reaction conducted using $5 \mathrm{~mol} \%$ of 1a, ${ }^{\mathrm{f}}$ Reaction conducted in the absence of $\mathrm{PhCO}_{2} \mathrm{H}$. ${ }^{\mathrm{g}}$ Opposite configuration was observed.

Having optimized the reaction conditions, we next investigated the scope of chiral squaramide catalyzed enantioselective Michael reaction of cyclohexanone with a variety of nitroolefins and the results are shown in Table 2. In addition to cyclohexanone 10, various nitroolefin derivatives with different substitution patterns on the aromatic ring in the presence of $10 \mathrm{~mol} \%$ of $1 \mathrm{a}$ with $10 \mathrm{~mol} \%$ of $\mathrm{PhCO}_{2} \mathrm{H}$ as the cocatalyst, gave the corresponding Michael adducts 12a-j with excellent diastereoselectivities (up to 98/2 $d r$ ) and enantioselectivities (up to 93\% ee) (Table 2, entries 1-10). However, the yields vared dramatically and no clear trend was observed with regard to the substituent on the aromatic ring. When aryl nitroolefins containing electron-withdrawing or electron-donating substituents on the aromatic ring (i.e. 11b-d, 11f, 11i and $\mathbf{1 1} \mathbf{j}$ ) were used for the reaction with $\mathbf{1 0}$, the reactions proceeded smoothly resulting in the formation of products in good yields (72-84\%, Table 2, entries 2-4, 6, 9 and 10). However, aryl nitroolefins 11e, 11g, and $11 \mathrm{~h}$, bearing 2-chloro, 4-trifluoro and 3-nitro groups, respectively, were exceptional, giving the producs in only low to moderate yields (41-60\%, Table 2, entries 5 , 7 and 8). Phenyl nitroolefin 11a without a substituent afforded the product in $60 \%$ yield (Table 2, entry 1). Heteroaromatic nitroolefins, such as 2 -thienyl nitroolefin 11l, gave a $75 \%$ of ee (Table 
2, entry 12). 2-Furyl nitroolefin $\mathbf{1 1 k}$, gave the product in $70 \%$ yield with $80 / 20 \mathrm{dr}$ and $81 \%$ ee (Table 2, entry 11). Other catalysts, such as $\mathbf{1 d}$, proved to be effective providing the products with opposite configuration in reasonable yields and good ee values (entries 13 and 14). Aliphatic nitroolefins displayed much less reactivity in this reaction, for example, when $(E)$-1nitropent-1-ene 11n was used, only trace amount of product was observed (Table 2, entry 15).

Table 2. Evaluation of the scope of the Michael addition of cyclohexanone $\mathbf{1 0}$ and nitroalken $11^{\mathrm{a}}$.

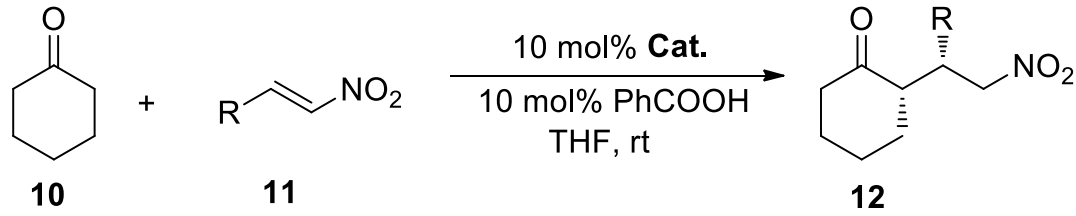

\begin{tabular}{|c|c|c|c|c|c|}
\hline Entry & Nitroolefin & Cat. & Product & $\begin{array}{l}\text { Yield } \\
(\%)^{\mathrm{b}, \mathrm{c}}\end{array}$ & ee $(\%)^{\mathrm{d}}$ \\
\hline 1 & $\mathrm{R}=\mathrm{Ph}(\mathbf{1 1} \mathbf{a})$ & $1 \mathbf{a}$ & $12 \mathbf{a}$ & $60(88: 12)$ & 93 \\
\hline 2 & $\mathrm{R}=4-\mathrm{F}-\mathrm{C}_{6} \mathrm{H}_{4}(\mathbf{1 1 b})$ & $\mathbf{1 a}$ & $12 b$ & $81(86: 14)$ & 82 \\
\hline 3 & $\mathrm{R}=4-\mathrm{Br}-\mathrm{C}_{6} \mathrm{H}_{4}(\mathbf{1 1 c})$ & $\mathbf{1 a}$ & $12 c$ & $80(87: 13)$ & 83 \\
\hline 4 & $\mathrm{R}=2-\mathrm{Br}-\mathrm{C}_{6} \mathrm{H}_{4}(\mathbf{1 1 d})$ & $1 \mathbf{a}$ & $12 d$ & $84(97: 3)$ & 84 \\
\hline 5 & $\mathrm{R}=2-\mathrm{Cl}-\mathrm{C}_{6} \mathrm{H}_{4}(\mathbf{1 1 e})$ & $\mathbf{1 a}$ & $12 \mathrm{e}$ & $60(98: 2)$ & 93 \\
\hline 6 & $\mathrm{R}=2,4-\mathrm{Cl}_{2}-\mathrm{C}_{6} \mathrm{H}_{3}(\mathbf{1 1 f})$ & $\mathbf{1 a}$ & $12 f$ & $80(80: 20)$ & 85 \\
\hline 7 & $\mathrm{R}=4-\mathrm{CF}_{3}-\mathrm{C}_{6} \mathrm{H}_{4}(\mathbf{1 1 g})$ & $\mathbf{1 a}$ & $12 \mathrm{~g}$ & $41(88: 12)$ & 80 \\
\hline 8 & $\mathrm{R}=3-\mathrm{NO}_{2}-\mathrm{C}_{6} \mathrm{H}_{4}(\mathbf{1 1 h})$ & $1 \mathbf{a}$ & $12 \mathrm{~h}$ & $50(86: 14)$ & 86 \\
\hline 9 & $\mathrm{R}=2-\mathrm{MeO}-\mathrm{C}_{6} \mathrm{H}_{4}(\mathbf{1 1 i})$ & $\mathbf{1 a}$ & $12 \mathbf{i}$ & $74(97: 3)$ & 81 \\
\hline 10 & $\mathrm{R}=4-\mathrm{Me}-\mathrm{C}_{6} \mathrm{H}_{4}(\mathbf{1 1} \mathbf{j})$ & $\mathbf{1 a}$ & $12 j$ & $72(83: 7)$ & 80 \\
\hline 11 & $\mathrm{R}=2$-Furyl (11k) & $1 \mathbf{a}$ & $12 k$ & $70(80: 20)$ & 81 \\
\hline 12 & $\mathrm{R}=$ 2-Thienyl (11l) & $1 \mathbf{a}$ & 121 & $71(83: 7)$ & 75 \\
\hline 13 & $\mathrm{R}=\mathrm{Ph}(\mathbf{1 1} \mathbf{a})$ & 1d & $12 \mathbf{a}$ & $60(90: 10)$ & $86^{\mathrm{e}}$ \\
\hline 14 & $\mathrm{R}=2-\mathrm{Cl}-\mathrm{C}_{6} \mathrm{H}_{4}(\mathbf{1 1 e})$ & $1 d$ & $12 \mathrm{e}$ & $55(96: 4)$ & $92^{\mathrm{e}}$ \\
\hline 15 & $\mathrm{R}=n-\operatorname{propyl}(\mathbf{1 1 n})$ & $1 \mathbf{a}$ & $12 \mathrm{~m}$ & Trace & $\mathrm{ND}$ \\
\hline
\end{tabular}

${ }^{a}$ Unless otherwise noted, the reactions were carried out with $0.2 \mathrm{mmol}$ of 11, $2.0 \mathrm{mmol}$ of cyclohexanone 10 in $1.0 \mathrm{~mL}$ of THF in the presence of $10 \mathrm{~mol} \%$ of catalyst $1 \mathrm{a}$ and $10 \mathrm{~mol} \%$ of $\mathrm{PhCO}_{2} \mathrm{H}$ for $48 \mathrm{~h}$. ${ }^{b}$ Isolated yield for both diastereoisomers, ${ }^{\mathrm{c}}$ Numbers in parenthesis correspond to the syn/anti ratio determined by ${ }^{1} \mathrm{H}$ NMR, ${ }^{\mathrm{d}}$ Enantiomeric excess of major diasteroisomer, determined by chiral HPLC, ${ }^{e}$ Opposite configuration was observed.

Besides monoketone 10, the catalytic effect of the bifunctional squaramides catalysts in Michael addition of diketones was also evaluated. After a brief optimization of reaction 
conditions, we found that $\mathrm{CH}_{2} \mathrm{Cl}_{2}$ was preferred as solvent with $1 \mathrm{~mol} \%$ catalyst $\mathbf{1 a}$ (Table 3, entry 7). Other solvents, e.g. toluene, THF, $n$-hexane, methanol, etc were also investigated, however, none of them gave better results (Table 3, entries 2-5). Neither reducing the catalyst loading from 1 to $0.5 \mathrm{~mol} \%$ (Table 3, entry 6) nor enhancing the catalyst loading to 2, 5, even 10 mol\% (Table 3, entries 1-8 and 9) benefited the enantioselectivity.

Table 3. Optimization of reaction conditions of the Michael addition of 2, 4-pentanedione 13a with nitrostyrene $11 \mathbf{a}^{\mathrm{a}}$

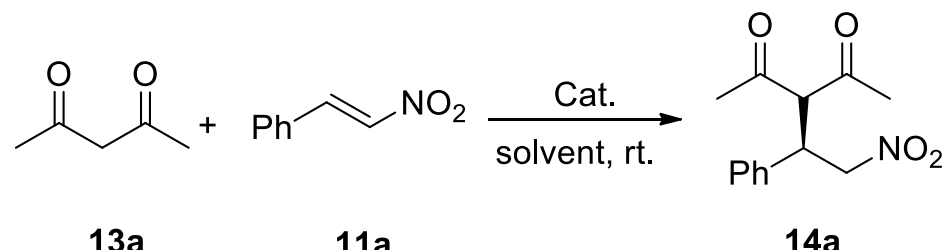

\begin{tabular}{ccccccc}
\hline Entry & Cat. & Solvent & $\begin{array}{c}\text { Cat. } \\
(\text { mol\% })\end{array}$ & $\begin{array}{c}\text { Time } \\
(\mathrm{h})\end{array}$ & $\begin{array}{c}\text { Yield } \\
(\%)^{\mathrm{b}}\end{array}$ & $\begin{array}{c}\text { ee } \\
(\%)^{\mathrm{c}}\end{array}$ \\
\hline 1 & $\mathbf{1 a}$ & $\mathrm{CH}_{2} \mathrm{Cl}_{2}$ & 10 & 12 & 94 & 87 \\
2 & $\mathbf{1 a}$ & toluene & 10 & 12 & 83 & 76 \\
3 & $\mathbf{1 a}$ & $\mathrm{THF}$ & 10 & 12 & 71 & 83 \\
4 & $\mathbf{1 a}$ & $n-\mathrm{Hexane}$ & 10 & 12 & 67 & 73 \\
5 & $\mathbf{1 a}$ & $\mathrm{MeOH}$ & 10 & 20 & 60 & 63 \\
6 & $\mathbf{1 a}$ & $\mathrm{CH}_{2} \mathrm{Cl}_{2}$ & 0.5 & 20 & 94 & 86 \\
7 & $\mathbf{1 a}$ & $\mathrm{CH}_{2} \mathrm{Cl}_{2}$ & 1 & 12 & 96 & 93 \\
8 & $\mathbf{1 a}$ & $\mathrm{CH}_{2} \mathrm{Cl}_{2}$ & 2 & 12 & 96 & 89 \\
9 & $\mathbf{1 a}$ & $\mathrm{CH}_{2} \mathrm{Cl}_{2}$ & 5 & 12 & 97 & 87 \\
10 & $\mathbf{1 b}$ & $\mathrm{CH}_{2} \mathrm{Cl}_{2}$ & 1 & 12 & 86 & $82^{\mathrm{d}}$ \\
11 & $\mathbf{1 c}$ & $\mathrm{CH}_{2} \mathrm{Cl}_{2}$ & 1 & 12 & 8 & 85 \\
12 & $\mathbf{1 d}$ & $\mathrm{CH}_{2} \mathrm{Cl}_{2}$ & 1 & 12 & 93 & $87^{\mathrm{d}}$ \\
13 & $\mathbf{2 a}$ & $\mathrm{CH}_{2} \mathrm{Cl}_{2}$ & 1 & 12 & 93 & 12 \\
14 & $\mathbf{2 b}$ & $\mathrm{CH}_{2} \mathrm{Cl}_{2}$ & 1 & 12 & 90 & 60 \\
15 & $\mathbf{3}$ & $\mathrm{CH}_{2} \mathrm{Cl}_{2}$ & 1 & 12 & 92 & 77 \\
\hline
\end{tabular}

${ }^{\text {a }}$ The reactions were carried out with $0.5 \mathrm{mmol}$ of 11a, $1.0 \mathrm{mmol}$ of 2,4-pentanedione 13a in the presence of specific amount of catalyst 1a, in $1.0 \mathrm{~mL}$ of solvent indicated for $12-20 \mathrm{~h} .{ }^{\mathrm{b}}$ Isolated yield, ${ }^{c}$ Determined by chiral HPLC. ${ }^{\mathrm{d} O p p o s i t e}$ configuration was observed.

The optimized conditions were then used to assess the activity of other chiral squaramides 1b-d, 2 and 3. As in the Michael additions of a monoketone, the combination of the pyrrolidine with cinchona alkaloid proved critical for this Michael addition. Again the chiral squaramideamine 1a, derived from L-proline and cinchonine, displayed higher selectivity; while the catalyst 
1b, possessing a cinchonidine backbone, was less effective, giving the product with opposite configuration in $86 \%$ yield and $82 \%$ ee, respectively (Table 3, entry 10 ). A lower yield but good enantioselectivity was observed when 1c was used in this reaction, which prepared from Dproline and cinchonine (entry 11). Furthermore, catalyst 1d, derived from D-proline and cinchonidine, induced higher enantioselectivity than $\mathbf{1 b}-\mathbf{c}$, giving the desired product in $93 \%$ yield and $87 \%$ ee (entry 12). These results demonstrated the significance of matching the chiralities of the two backbones embedded in the catalysts on the reactivity and enantioselectivity. Lastly, two catalysts having the core structure of cinchonine-substituted squaramide but differing in the pyrrolidine moiety were examined, for example $\mathbf{2}$ and $\mathbf{3}$, and all were found to provide the product in good yield but lower ee value (Table 3, entries 13-15).

With the optimal reaction conditions in hand, we next examined other nitroolefins and 1,3dicarbonyl compounds to expand the substrate scope of catalyst 1a, and the results are shown in Table 4. Various electron-poor and electron-rich nitroolefins with various substitution patterns on the aromatic ring reacted smoothly with 2,4-pentanedione 13a in the presence of $1 \mathrm{~mol} \%$ of $\mathbf{1 a}$, giving the corresponding Michael adducts 14a-h in high to excellent yields (88-96\%), with high enantioselectivities ( $81-96 \%$ ee) (Table 4, entries 1-8), including the heteroaromatic nitroolefin, such as 111, afforded the product in $83 \%$ ee (Table 4 , entry 7 ).

Table 4. Variation of electrophile and nucleophile in the Michael addition of 2,4-pentanediones $\mathbf{1 3}$ with nitroalkenes $\mathbf{1 1}^{\mathrm{a}}$

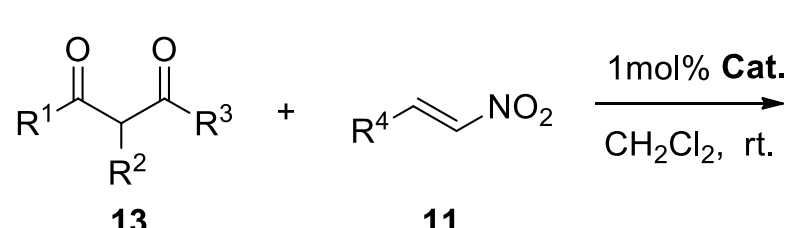

13
11

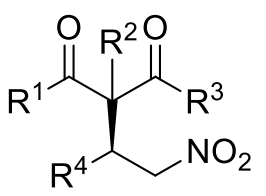

14

\begin{tabular}{|c|c|c|c|c|c|c|c|c|}
\hline \multirow{2}{*}{$\frac{\text { Entry }}{1}$} & \multicolumn{2}{|c|}{ 1,3-Dicarbonyl compound } & \multicolumn{2}{|l|}{ Nitroolefin } & \multirow{2}{*}{$\begin{array}{r}\text { Cat. } \\
\mathbf{1 a}\end{array}$} & \multirow{2}{*}{$\begin{array}{l}\text { Prod } \\
\text { uct } \\
\mathbf{1 4 a}\end{array}$} & \multirow{2}{*}{$\begin{array}{c}\text { yield } \\
(\%)^{\mathrm{b}, \mathrm{c}}\end{array}$} & \multirow{2}{*}{$\begin{array}{r}\mathrm{ee} \\
(\%) \\
93\end{array}$} \\
\hline & $\mathrm{R}^{1}=\mathrm{R}^{3}=\mathrm{Me}, \mathrm{R}^{2}=\mathrm{H}$ & $13 \mathbf{a}$ & $\mathrm{R}^{4}=\mathrm{Ph}$ & $11 a$ & & & & \\
\hline 2 & $\mathrm{R}^{1}=\mathrm{R}^{3}=\mathrm{Me}, \mathrm{R}^{2}=\mathrm{H}$ & $13 \mathbf{a}$ & $\mathrm{R}^{4}=4-\mathrm{F}-\mathrm{C}_{6} \mathrm{H}_{4}$ & $11 b$ & $1 \mathbf{a}$ & $14 \mathrm{~b}$ & 88 & 88 \\
\hline 3 & $\mathrm{R}^{1}=\mathrm{R}^{3}=\mathrm{Me}, \mathrm{R}^{2}=\mathrm{H}$ & 13a & $\mathrm{R}^{4}=4-\mathrm{Br}-\mathrm{C}_{6} \mathrm{H}_{4}$ & $11 \mathrm{c}$ & 1a & $14 c$ & 92 & 81 \\
\hline 4 & $\mathrm{R}^{1}=\mathrm{R}^{3}=\mathrm{Me}, \mathrm{R}^{2}=\mathrm{H}$ & $13 \mathbf{a}$ & $\mathrm{R}^{4}=2-\mathrm{Br}-\mathrm{C}_{6} \mathrm{H}_{4}$ & 11d & $1 \mathbf{a}$ & 14d & 90 & 92 \\
\hline 5 & $\mathrm{R}^{1}=\mathrm{R}^{3}=\mathrm{Me}, \mathrm{R}^{2}=\mathrm{H}$ & 13a & $\mathrm{R}^{4}=4-\mathrm{Me}-\mathrm{C}_{6} \mathrm{H}_{4}$ & $\mathbf{1 1} \mathbf{j}$ & $1 \mathbf{a}$ & $14 \mathrm{e}$ & 91 & 88 \\
\hline
\end{tabular}


Table 4. Continued

\begin{tabular}{|c|c|c|c|c|c|c|c|c|}
\hline \multirow{2}{*}{$\frac{\text { Entry }}{6}$} & \multicolumn{2}{|c|}{ 1,3-Dicarbonyl compound } & \multicolumn{2}{|l|}{ Nitroolefin } & \multirow{2}{*}{$\begin{array}{r}\text { Cat. } \\
\mathbf{1 a}\end{array}$} & \multirow{2}{*}{$\begin{array}{r}\text { Prod } \\
\text { uct }\end{array}$} & \multirow{2}{*}{$\begin{array}{c}\text { yield } \\
(\%)^{\mathrm{b}, \mathrm{c}}\end{array}$} & \multirow{2}{*}{$\begin{array}{c}\begin{array}{c}\text { ee } \\
(\%)^{\mathrm{d}}\end{array} \\
73\end{array}$} \\
\hline & $\mathrm{R}^{1}=\mathrm{R}^{3}=\mathrm{Me}, \mathrm{R}^{2}=\mathrm{H}$ & $13 \mathbf{a}$ & $\mathrm{R}^{4}=2$-Furyl & $11 k$ & & & & \\
\hline 7 & $\mathrm{R}^{1}=\mathrm{R}^{3}=\mathrm{Me}, \mathrm{R}^{2}=\mathrm{H}$ & $13 \mathbf{a}$ & $\mathrm{R}^{4}=2$-Thienyl & 11I & $1 \mathbf{a}$ & $14 \mathrm{~g}$ & 89 & 83 \\
\hline 8 & $\mathrm{R}^{1}=\mathrm{R}^{3}=\mathrm{Me}, \mathrm{R}^{2}=\mathrm{H}$ & $13 \mathbf{a}$ & $\begin{array}{c}\mathrm{R}^{4}=4-\mathrm{MeO}- \\
\mathrm{C}_{6} \mathrm{H}_{4}\end{array}$ & $11 \mathrm{~m}$ & $1 \mathbf{a}$ & $14 \mathrm{~h}$ & 92 & 96 \\
\hline 9 & $\begin{array}{c}\mathrm{R}^{1}=\mathrm{Ph}, \mathrm{R}^{2}=\mathrm{H}, \mathrm{R}^{3}= \\
\mathrm{OEt}\end{array}$ & 13b & $\mathrm{R}^{4}=\mathrm{Ph}$ & 11a & 1a & $14 i$ & $\begin{array}{l}90 \\
(1: 1)\end{array}$ & $85 / 84$ \\
\hline 10 & $\begin{aligned} \mathrm{R}^{1}, \mathrm{R}^{2} & =-\left(\mathrm{CH}_{2}\right)_{3^{-}}, \mathrm{R}^{3} \\
& =\mathrm{Me}\end{aligned}$ & $13 c$ & $\mathrm{R}^{4}=\mathrm{Ph}$ & 11a & $1 \mathbf{a}$ & $14 j$ & $\begin{array}{l}81 \\
(1: 1)\end{array}$ & $88 / 86$ \\
\hline 11 & $\begin{aligned} \mathrm{R}^{1}, \mathrm{R}^{2} & =-\left(\mathrm{CH}_{2}\right)_{3^{-}}, \mathrm{R}^{3} \\
& =\mathrm{OEt}\end{aligned}$ & 13d & $\mathrm{R}^{4}=\mathrm{Ph}$ & 11a & $1 \mathbf{a}$ & $14 k$ & $\begin{array}{c}85 \\
(24: 1)\end{array}$ & $83 / 87$ \\
\hline 12 & $\begin{array}{c}\mathrm{R}^{1}=\mathrm{Me}, \mathrm{R}^{2}=\mathrm{H}, \mathrm{R}^{3}= \\
\mathrm{OMe}\end{array}$ & $13 e$ & $\mathrm{R}^{4}=\mathrm{Ph}$ & 11a & $1 \mathbf{a}$ & 141 & $\begin{array}{c}92 \\
(1.1: 1)\end{array}$ & $86 / 80$ \\
\hline 13 & $\begin{array}{c}\mathrm{R}^{1}=\mathrm{Me}, \mathrm{R}^{2}=\mathrm{H}, \mathrm{R}^{3}= \\
\mathrm{OEt}\end{array}$ & 13f & $\mathrm{R}^{4}=\mathrm{Ph}$ & 11a & $1 \mathbf{a}$ & $14 m$ & $\begin{array}{c}91 \\
(1.1: 1)\end{array}$ & $87 / 86$ \\
\hline 14 & $\begin{array}{c}\mathrm{R}^{1}=\mathrm{Me}, \mathrm{R}^{2}=\mathrm{H}, \mathrm{R}^{3}= \\
\mathrm{O} t \mathrm{Bu}\end{array}$ & $13 \mathrm{~g}$ & $\mathrm{R}^{4}=\mathrm{Ph}$ & 11a & $\mathbf{1 a}$ & $14 n$ & $\begin{array}{c}86 \\
(12: 1)\end{array}$ & $86 / 86$ \\
\hline 15 & $\begin{array}{c}\mathrm{R}^{1}=\mathrm{Et}, \mathrm{R}^{2}=\mathrm{H}, \mathrm{R}^{3}= \\
\mathrm{OMe}\end{array}$ & $13 \mathrm{~h}$ & $\mathrm{R}^{4}=\mathrm{Ph}$ & 11a & $1 \mathbf{a}$ & 140 & $\begin{array}{l}90 \\
(1: 1)\end{array}$ & $86 / 80$ \\
\hline 16 & $\mathrm{R}^{1}=\mathrm{R}^{3}=\mathrm{Me}, \mathrm{R}^{2}=\mathrm{H}$ & 13a & $\mathrm{R}^{4}=\mathrm{Ph}$ & 11a & $1 d$ & $14 a$ & 89 & $87^{\mathrm{e}}$ \\
\hline 17 & $\mathrm{R}^{1}=\mathrm{R}^{3}=\mathrm{Me}, \mathrm{R}^{2}=\mathrm{H}$ & 13a & $\begin{array}{c}\mathrm{R}^{4}=4-\mathrm{MeO}- \\
\mathrm{C}_{6} \mathrm{H}_{4}\end{array}$ & $11 \mathrm{~m}$ & 1d & $14 \mathrm{~h}$ & 92 & $92^{\mathrm{e}}$ \\
\hline
\end{tabular}

${ }^{a}$ Unless otherwise noted, the reactions were carried out with $0.2 \mathrm{mmol}$ of $\mathbf{1 1}, 0.4 \mathrm{mmol}$ of $\mathbf{1 3}$ in $1.0 \mathrm{~mL}$ of $\mathrm{CH}_{2} \mathrm{Cl}_{2}$ in the presence of $1 \mathrm{~mol} \%$ of catalyst $\mathbf{1 a}$ for $12-36 \mathrm{~h}$. ${ }^{\mathrm{b}}$ Isolated yield; ${ }^{\mathrm{c}}$ Numbers in parenthesis correspond to the syn/anti ratio determined by ${ }^{1} \mathrm{H}$ NMR. ${ }^{\mathrm{d}}$ Values are listed for major and minor diastereomers, respectively, and are determined by HPLC. ${ }^{e}$ Opposite configuration was observed.

When comes to other 1,3-dicarbonyl compounds $\mathbf{1 3 b}-\mathbf{h}$, in the reaction with 11a, all reactions proceeded in good to excellent yields and, generally, good enantioselectivities (Table 4, entries 9-15). Although several of the reactions proceeded with lower diastereoselectivity, each of the diastereomers was formed in very good enantioselectivity. As expected, employment of 
catalyst $1 \mathbf{d}$ led to high selectivity and enantioselectivity and opposite configuration was observed (Table 4, entries 16 and 17).

In addition, we also investigated the use of these nitroalkanes as starting materials for further transformation. For example, as shown in Scheme 3, in the presence of zinc in acetic acid, $\mathbf{1 4} \mathbf{j}$ was smoothly reduced to corresponding amine 15 in $86 \%$ yield.

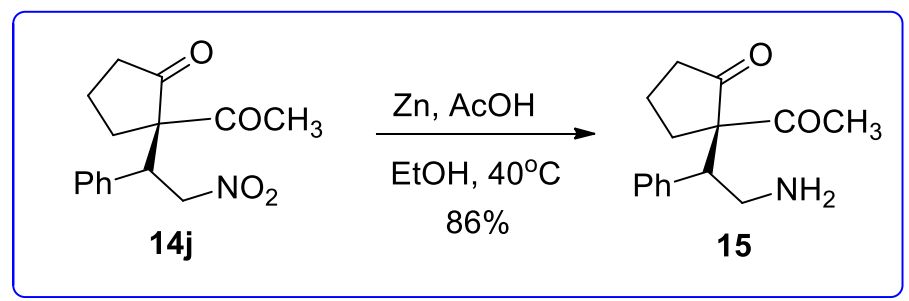

Scheme 3. Further transformation of the Michael adduct.

\section{Conclusions}

In conclusion, we have designed a new class of bifunctional chiral squaramide-amine catalysts by a rational combination of readily available pyrrolidines with cinchona alkaloids. The catalyst 1a exhibited the best performance in the asymmetric addition of both mono- and diketones to a broad range of nitroalkenes. The corresponding products can be obtained in moderate to high yields with excellent enantioselectivities and diastereoselectivities under mild conditions. The match of the chiralities between two backbones embedded in catalysts is also critical for improving enantioselectivity.

\section{Experimental Section}

General. Tetrahydrofuran, diethyl ether and toluene were dried over $\mathrm{Na} / \mathrm{benzophenone,}$ dichloromethane was dried over $\mathrm{CaH}_{2}$ and distilled prior to use. Reaction progress was monitored using analytical thin-layer chromatography (TLC) on $0.25 \mathrm{~mm}$ Merck F-254 silica gel glass plates. Visualization was achieved by UV light $(254 \mathrm{~nm})$. Flash chromatography was performed with silica gel (Merck, 230-400 mesh). Unless otherwise noted, all NMR spectra were recorded using $\mathrm{CDCl}_{3}$ as the solvent with reference to residual $\mathrm{CHCl}_{3}\left({ }^{1} \mathrm{H}\right.$ at $7.24 \mathrm{ppm}$ and, ${ }^{13} \mathrm{C}$ at $77.0 \mathrm{ppm}$ ). Optical rotations were measured at room temperature on a Perkin-Elmer 241MC automatic polarimeter (concentration in $\mathrm{g} / 100 \mathrm{~mL}$ ). Melting points were obtained on a micromelting apparatus and the data were uncorrected. Determination of $\%$ ee was achieved using a chiral HPLC equipped with a chiralpak AD or OD column with $n$-hexanes: 2-propanol as the mobile phase at a flow rate of $1 \mathrm{~mL} / \mathrm{min}$. 


\section{Procedure for the preparation of catalyst (1a)}

To a solution of diethyl squarate $5(0.1 \mathrm{mmol})$ in EtOH $(5 \mathrm{~mL})$ with TEA was added $(S)$-2amino-1- $N$-Boc-pyrrolidine $6(0.11 \mathrm{mmol}) \mathrm{EtOH}(5 \mathrm{~mL})$ at room temperature. The reaction mixture was stirred overnight and subjected to column chromatography to afford 7 (87\%). To a solution of $7(0.1 \mathrm{mmol})$ and amine $8(0.12 \mathrm{mmol})$ in EtOH $(10 \mathrm{~mL})$ was added TEA $(0.1 \mathrm{mmol})$. After $36 \mathrm{~h}$, the reaction mixture was concentrated and subjected to column chromatography to afford squaramide 9. The squaramide 9 was dissolved in a mixture of $\mathrm{HCl} / \mathrm{EtOH}(12 \mathrm{~mL} / 60 \mathrm{~mL})$ and stirred for $12 \mathrm{~h}$. The mixture was basified with concentrated ammonia solution and extracted with $\mathrm{CH}_{2} \mathrm{Cl}_{2}(2 \times 40 \mathrm{~mL})$. After the removal of the solvent in vacuum, the residue was purified through flash column chromatography on silica gel (eluent: methanol / TEA = 10:1) giving 1a as a white solid in $88 \%$ yield. ${ }^{1} \mathrm{H}$ NMR $\left(400 \mathrm{MHz} \mathrm{CDCl}_{3}\right) \delta=0.80-1.87(\mathrm{~m}, 9 \mathrm{H}), 2.10-3.95$ (m, $13 \mathrm{H})$, 5.01-5.11 (m, 2H), 5.72-5.80 (m, 1H), 6.25 (s, br, $1 \mathrm{H}), 7.57-8.79(\mathrm{~m}, 6 \mathrm{H}) \mathrm{ppm},{ }^{13} \mathrm{C} \mathrm{NMR}$ $\left(100 \mathrm{MHz}, \mathrm{CDCl}_{3}\right) \delta: 183.7,182.5,167.9,150.4,150.2,148.8,147.2,140.0,130.4,129.9,127.6$, 127.1, 124.0, 119.5, 115.4, 60.5, 49.7, 46.6, 45.5, 44.8, 39.3, 29.8, 28.5, 27.9, 26.7, 25.7, 24.2. HRMS (ESI) calcd for $\mathrm{C}_{28} \mathrm{H}_{33} \mathrm{~N}_{5} \mathrm{O}_{2} \mathrm{H}[\mathrm{M}+\mathrm{H}]^{+} 472.2713$; found 472.2703.

\section{Representative procedure for the asymmetric Michael reaction of nitroolefin (11a) with cyclohexanone (10)}

The organocatalyst $1 \mathrm{a}(0.05 \mathrm{mmol}), \mathrm{PhCO}_{2} \mathrm{H}(0.05 \mathrm{mmol})$ and cyclohexanone $10(5.0 \mathrm{mmol})$ were stirred in $2 \mathrm{~mL}$ of THF for $10 \mathrm{~min}$ at room temperature. $\beta$-nitrostyrene $11 \mathrm{a}(0.5 \mathrm{mmol})$ was then added and the reaction mixture was stirred for $48 \mathrm{~h}$. The reaction mixture was concentrated under reduced pressure, and the residue was purified by column chromatography on silica gel (petroleum ether/ethyl acetate (6:1)) to give the corresponding pure Michael product 12a (60\%) as a white solid. ${ }^{1} \mathrm{H}$ NMR $\left(400 \mathrm{MHz}, \mathrm{CDCl}_{3}\right) \delta=7.36-7.23(\mathrm{~m}, 3 \mathrm{H}), 7.18-7.15(\mathrm{~m}, 2 \mathrm{H}), 4.94$ $(\mathrm{dd}, J=12.5,4.5 \mathrm{~Hz}, 1 \mathrm{H}), 4.64(\mathrm{dd}, J=12.5,9.9 \mathrm{~Hz}, 1 \mathrm{H}), 3.76(\mathrm{td}, J=9.9,4.5 \mathrm{~Hz}, 1 \mathrm{H}), 2.74-$ $2.64(\mathrm{~m}, 1 \mathrm{H}), 2.54-2.33(\mathrm{~m}, 2 \mathrm{H}), 2.13-2.02(\mathrm{~m}, 1 \mathrm{H}), 1.83-1.63(\mathrm{~m}, 3 \mathrm{H}), 1.58-1.48(\mathrm{~m}, 1 \mathrm{H})$, 1.33-1.13 (m, 1H). ${ }^{13} \mathrm{C}$ NMR (100 MHz, $\left.\mathrm{CDCl}_{3}\right) \delta \square 212.0,137.9,129.2,128.4,128.1,79.1$, $52.8,44.2,43.0,33.5,28.6,25.2$. The ee was determined by HPLC using Chiralpak AD column with $10 \% i-\mathrm{PrOH}$ in hexane and the detector set at $220 \mathrm{~nm}$.

\section{General procedure for the asymmetric Michael reaction of nitroolefin (11) with diketones} (13)

To a solution of nitroolefin $11(0.5 \mathrm{mmol})$ in $\mathrm{CH}_{2} \mathrm{Cl}_{2}(2.0 \mathrm{~mL})$ was added catalyst $1 \mathrm{a}(0.005$ $\mathrm{mmol})$ and 1,3-dicarbonyl compound $13(5.0 \mathrm{mmol})$. Upon consumption of nitroolefin substrate (monitored by TLC), the reaction mixture was concentrated and purified by column chromatography to afford the conjugate addition product 14. 


\section{Supplementary Material}

Representative procedures for preparation of catalysts; the procedure for the enantioselective Michael addition of ketones and nitroolefins; spectroscopic data of ligands 1-3; products 12a-l, 14a-l, and representative HPLC spectra of products 12 and 14.

\section{Acknowledgements}

We are grateful to the NSFC $(20872116,20972121,91017005)$, the Program for New Century Excellent Talents in University (NCET-10-0625), the National Mega Project on Major Drug Development (2009ZX09301-014-1), and the Research Fund for the Doctoral Program of Higher Education of China (20100141110021) for support of this research. We also thank Professors Guofu Qiu and Xingang Zhang for NMR measurements. Zongquan Liao and Jun Zhu are thanked for assistance in the preparation of 2-aminomethyl-1- $N$-Boc-pyrrolidine and certain nitroalkenes.

\section{References}

1. For selected reviews on organocatalytic asymmetric Michael addition reaction, see. (a) Tsogoeva, S. B. Eur. J. Org. Chem. 2007, 11, 1701. (b) Almasi, D.; Alonso, A. D.; Najera, C. Tetrahedron: Asymmetry 2007, 18, 299. (c) Perlmutter, P. Conjugate Addition Reactions in Organic Synthesis. Pergamon Press: Oxford, 1992. (d) Seayad, J.; List, B. Org. Biomol. Chem. 2005, 3, 719. (e) List, B.; Yang, J. W. Science 2006, 313, 1584. (f) MacMillan, D. W. C. Nature 2008, 455, 304. (g) Dondoni, A.; Massi, A. Angew. Chem., Int. Ed. 2008, 47, 4638.

2. For recent reviews, see. (a) Sibi, M. P.; Manyem, S. Tetrahedron 2000, 56, 8033. (b) Krause, N. Hoffmann-Roder, A. Synthesis 2001, 2, 171. (c) Ono, N. The Nitro Group in Organic Synthesis. Wiley-VCH: New York, 2001. (d) Czekelius, C. Carreira, E. M. Angew. Chem., Int. Ed. 2005, 44, 612.

3. (a) Betancort, J. M.; Barbas, C. F. Org. Lett. 2001, 3, 3737. (b) Betancort, J. M.; Sakthivel, K.; Thayumanavan, R.; Barbas, C. F. Tetrahedron Lett. 2001, 42, 4441. (c) List, B. Pojarliev, P.; Martin, H. J. Org. Lett. 2001, 3, 2423.

4. For recent examples, see. (a) Wang, L. L.; Xu, X. Y.; Huang, J.; Peng, L.; Huang, Q. C.; Wang, L. X. Lett. Org. Chem. 2010, 7, 367. (b) Li, B. L.; Wang, Y. F.; Luo, S. P.; Zhong, A. G.; Li, Z. B.; Du, X. H.; Xu, D. Q. Eur. J. Org. Chem. 2010, 656. (c) Moon, H. W.; Kim, D. Y. Tetrahedron Lett. 2010, 51, 2906. (d) Yang,Y. Q; Chen, X. K.; Xiao, H.; Liu, W.; Zhao, G. Chem. Commun. 2010, 46, 4130.

5. For recent examples, see. (a) Bai, J. F.; Xu, X. Y.; Huang, Q. C.; Peng, L.; Wang, L. X. Tetrahedron Lett. 2010, 51, 2803. (b) Zheng, Z. L.; Perkins, B. L.; Ni, B. K. J. Am. Chem. 
Soc. 2010, 132, 50. (c) Wiesner, M.; Upert, G.; Angelici, G.; Wennemers, H. J. Am. Chem. Soc. 2010, 132, 6.

6. For selected reviews on hydrogen bonding catalysis, see. (a) Zhang, Z. G.; Schreiner, P. R.; Chem. Soc. Rev. 2009, 38, 1187. (b) Yu, X. H.; Wang, W. Chem. Asian J. 2008, 3, 516. (c) Connon, S. J. Chem. Commun. 2008, 22, 2499. (d) Taylor, M. S.; Jacobsen, E. N. Angew. Chem., Int. Ed. 2006, 45, 1520. (e) Akiyama, T.; Itoh, J.; Fuchibe, K. Adv. Synth. Catal. 2006, 348, 999. (f) Connon, S. J. Chem. Eur. J. 2006, 12, 5418.

7. (a) Connon, S. J. Synlett 2009, 354. (b) Doyle, A. G.; Jacobsen, E. N. Chem. Rev. 2007, 107, 5713. (c) Chen, J. R.; Lu, H. H.; Li, X. Y.; Cheng, L.; Wan, J.; Xiao, W. J. Org. Lett. 2005, 7, 4543. (d) Liu, X. H.; Lin, L. L.; Feng, X. M. Chem. Commun. 2009, 6145.

8. Huang, H. B.; Jacobsen, E. N. J. Am. Chem. Soc. 2006, 128, 7170.

9. (a) Chen, J. R.; Cao, Y. J.; Zou,Y. Q.; Tan, F.; Fu, L.; Zhu, X. Y.; Xiao, W. J. Org. Biomol. Chem. 2010, 8, 1275. (b) Chen, J. R.; Zou, Y. Q.; Fu, L.; Ren, F.; Tan, F.; Xiao, W. J. Tetrahedron 2010, 66, 5367. (c) Chen, J. R.; An, X. L.; Zhu, X. Y.; Wang, X. F.; Xiao, W. J. J. Org. Chem. 2008, 73, 6006.

10. Pina, M. N.; Rotger, C.; Soberats, B.; Ballester, P.; Deya, P. M.; Costa, A. Chem. Commun. 2007, 963.

11. (a) Rotger, C.; Pina, M. N.; Vega, M.; Ballester, P.; Deya, P. M.; Costa, A. Angew. Chem., Int. Ed. 2006, 45, 6844. (b) Rotger, M. C.; Pina, M. N.; Frontera, A.; Martorell, G..; Ballester, P.; Deya, P. M.; Costa, A. J. Org. Chem. 2004, 69, 2302.

12. For representative examples of squaric acid-derived organocatalysts, see. (a) Malerich, J. P.; Hagihara, K.; Rawal, V. H. J. Am. Chem. Soc. 2008, 130, 14416. (b) Qian, Y.; Ma,G. Y.; Lv, A. F.; Zhu, H. L.; Zhao, J.; Rawal, V. H. Chem. Commun. 2010, 46, 3004. (c) Zhu, Y.; Malerich, J. P.; Rawal, V. H. Angew. Chem., Int. Ed. 2010, 49, 153. (d) Konishi, H.; Lam, T. Y.; Malerich, J. P.; Rawal, V. H. Org. Lett. 2010, 12, 2028. (e) Xu, D. Q.; Wang, Y. F.; Zhang, W.; Luo, S. P.; Zhong, A. G.; Xia, A. B.; Xu, Z. Y. Chem. Eur. J. 2010, 16, 4177. (f) Jang, H. B.; Rho, H. S.; Oh, J. S.; Nam, E. H.; Park, S. E.; Bae, H. Y.; Song, C. E. Org. Biomol. Chem. 2010, 8, 3918. (g) Yang, W.; Du, D. M. Org. Lett. 2010, 12, 5450.

13. For our work in applying squaric acid derivatives in asymmetic catalysis, see. (a) Zhou, $\mathrm{H}$. B.; Lu, S. M.; Xie, R. G. Chan, A. S. C.; Yang, T. K. Tetrahedron Lett. 2001, 42, 1107. (b) Zhou, H. B.; Lu, S. M.; Xie, R. G.; Zhou, Z. Y.; Choi, M. C. K.; Chan, A. S. C.; Yang, T. K. Tetrahedron 2001, 57, 9325. (c) Lu, S. M.; Zhou, H. B.; Xie, R. G.; Zhou, Z. Y.; Chan, A. S. C.; Yang, T. K. Acta. Chim. Sinica 2001, 59, 587. (d) Zhang, J.; Zhou, H. B.; et al. Tetrahedron: Asymmetry 2001, 12, 1907. (e) Zhang, J.; Zhou, H. B.; Xie, R. G. Curr. Org. Chem. 2002, 6, 865. (f) Jin, X. Q.; Min, Q. Q.; Zheng, Y. F.; Wang, P. C.; Zhu, J.; Zhou, H. B. Arkivoc 2010, (xi), 322.

14. For representative examples of pyrrolidine-derived organocatalysts, see. (a) Alexakis, A.; Andrey, O. Org. Lett. 2002, 4, 3611. (b) Mase, N.; Thayumanavan, R.; Tanaka, F.; Barbas, C. F. Org. Lett. 2004, 6, 2527. (c) Ishii, T.; Fujioka, S.; Sekiguchi, Y.; Kotsuki, H. J. Am. 
Chem. Soc. 2004, 126, 9558. (d) Vishnumaya, V. K. Singh, Org. Lett. 2007, 9, 1117. (e) Zhu, S. L.; Yu, S. Y. Ma, D. W. Angew. Chem., Int. Ed. 2008, 47, 545.

15. For general reviews on cinchona alkaloids and their derivatives-catalyzed reactions, see: (a) Kacprzak, K.; Gawronski, J. Synthesis 2001, 961. (b) Chen, Y. G.; McDaid, P.; Deng, L. Chem. Rev. 2003, 103, 2965. (c) Chen, Y. C. Synlett 2008, 1919.

16. For selected examples of the utility of amino alcohols in organocatalysis, see. (a) Liu, X.; Lu,Y. Org. Biomol. Chem. 2010, 8, 4063. (b) Reyes, E.; Vicario, J. L.; Badia, D.; Carrillo, L. Org. Lett. 2006, 8, 6135. 